\title{
Evaluation of Hospital's Emergency Departments According to User Requirements
}

\author{
By Ayşe Hazal Aygün ${ }^{1}$, Çilen Erçin ${ }^{1 *}$
}

\begin{abstract}
Hospitals are large and complex structures that provide 24-hour healthcare. These structures, where many different functions are combined, are constantly changing and developing with innovations in health, technique, and economy. With the technological developments in the world, population growth, the desire to live healthier and longer, hospital structures are reshaped. These developments best define the changes made in programming according to the user needs. In order for hospital buildings to provide health services for many years, they must be durable and designed with developments in the future which can happen. Emergency departments are from the internal units of the hospital. The duty of the emergency department is to bring the patients to the emergency service, to make the first intervention to the patient according to the emergency situation, and to provide the best care to the patient by directing them to the required unit. The emergency department architecture must take into consideration human health while meeting patient and user needs. Emergency departments have evolved from the past to today in line with the new needs of the users. In this study, the space requirements and general design factors of emergency departments are explained.
\end{abstract}

Keywords: Hospitals, Users, Emergency Departments, User Needs, Space Requirements

\section{Introduction}

Hospitals are large and complex buildings that provide health services 24 hours a day. Emergency services are one of the most important parts of the hospital. The duty of emergency services; 7 days, 24 hours a day, to reach and provide emergency or nonemergency patients, as well as to create and manage an action plan for disaster situations. The emergency departments take on a central role during disasters. In addition to adapting rapidly and integrating efficiently into the overall disaster response, it must remain resilient in order to absorb the impact of the ongoing event, while continuing to provide adequate care for both disaster and routine emergency patients in a safe environment.

Emergency services are units that serve all segments of society. A large part of the society in the world applies to the emergency room for the solution to health problems. Therefore, emergency services are in an important position between the hospital and the community. There are innovations and developments in the fields of health and health structures every day. With these developments, user needs and health structures are being reshaped.

The architectural structure of emergency services affects issues such as ensuring the best efficiency during use, and patient and employee satisfaction. It is very important to establish an appropriate emergency department, ensure integrity with the hospital, and be 
open to developments. In emergency planning, the priority should be to provide medical support to the patient as quickly as possible. In addition to places such as entrance and waiting areas, treatment and observation areas, diagnostic areas, which play a major role in the formation of the emergency department, technical, psychological, and aesthetical needs should be considered. At the same time, the changes that emergency services may need in the coming years should be considered and open to developments. That's why it requires extensive work when designing emergency services.

Emergency departments should be designed to create a healthy, safe, and comfortable area in line with the required spaces and user requirements, after environmental examination and information synthesis.

\subsection{Aims and Scope}

In this study, hospital and emergency departments will be examined according to user requirements.

This study aims to explain emergency departments in hospitals, space requirements of the emergency departments, and general design factors of the emergency departments.

\subsection{Methodology}

This study seeks to employ the use of secondary data sources. The sources will comprise articles sourced from different articles, thesis', books that are related to the hospitals, emergency departments, and user needs. These sources analyzed to understand user needs in emergency departments.

\section{General Information}

\subsection{User Needs}

User needs are determined with the problems and wishes of the users. The product or service designed according to the needs considered for user preferences gains value. Products or services that meet user needs are more preferred by users. Therefore, designs should be designed user-centered as explained with steps in Figure 1.

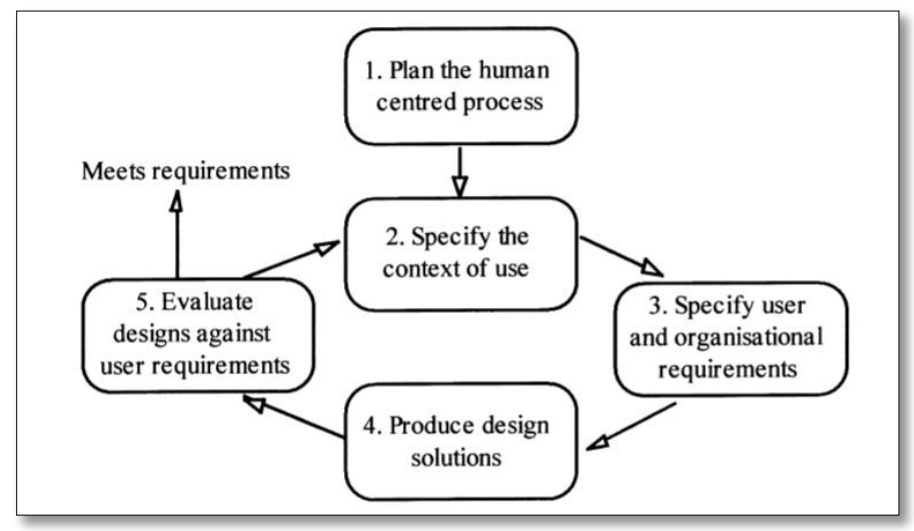

Figure 1: User-Centered Design Activities (Bevan, 1999). 


\subsection{Development of Emergency Departments Depending on Needs in the Historical Process}

The great development in the post-war era; the specialization in medicine, the decrease in the number of general practitioners, the development of hospital-based medical technology, and the great expectations of the people have made a big impact on history. Worldwide, there was a sharp increase of $400 \%$ in emergency visits after the end of World War II between 1940-1955.

In an article titled "Hospital" published in 1957, it was emphasized that emergency rooms, specialist diagnosis, and care are a vital factor in the relationship of the center, hospital, and community, and the reputation of an emergency room is directly related to the satisfaction of the patients coming to that emergency department and the experience of the emergency physicians. Discussion of the views in emergency planning has encouraged the planning of emergency, accessible, wide, and open patient care areas and played a major role in the expansion of the emergency department.

In the early 1960s, the emergence of hospital emergency action plans and the revival techniques of critically ill patients advanced. At the same time, the increase in the number of non-urgent patient visits forced emergency services to resemble emergency patient care clinics. Medical hospitals were very experienced in non-emergency patient care, and the appropriateness of performing these treatments in the emergency room was discussed, and as a result, emergency care departments changed towards an emergency care clinic in the 1970s.

In 1973, the Emergency Medicine Service System was enacted and the law ensured that local administrations were given appropriations to develop emergency services. A universal frequency " 911 " was established and a radio frequency was created for emergency services. An increase in the number of emergency patients and success achieved was observed as a result of the development of the emergency service on a national basis. In 1979, the Emergency Department was accepted as the 23rd medical branch. Parallel to the development of education and practice standards, emergency services have reached the current definition from the past 'emergency room'. The last mission of the Emergency Services has been declared as 'always accessible care' and the emergency medical community has made emergency services multifunctional, changeable, flexibly planned departments.

The increasing budget deficit and patient care costs, rapidly changing social values and technological developments continued in the 1990s in the 1980s. With 2010, budgets were allocated to emergency medicine and emergency aid with a large share. After these developments, emergency departments have continued to evolve until today (Aydin and Uysal, 2010; Ciplak, 2007; Sen, 2009).

\subsection{Emergency Departments}

In medical science, emergency means the patient's need for medical care without wasting time. Emergency department; is one of the internal units of the hospital structure and at the same time, it is the window of the hospital structure opened to the public with the level of service it provides to the patients. The purpose of emergency service is to bring the patients to the emergency room, to make the first intervention to the patient according to the emergency situation, and to provide the best care to the patient by directing them 
to the required unit. This includes patients requiring resuscitation and those with emergent, urgent, semi-urgent, and less-urgent conditions (Atalay, et al., 2017).

Emergency departments should also be able to provide the necessary space and medical equipment capacity for disaster situations. The purpose of emergency service is to bring the patients to the emergency room, to make the first intervention to the patient according to the emergency situation, and to provide the best care to the patient by directing them to the required unit.

First Level Emergency Departments should have a treatment area of up to $400 \mathrm{~m}^{2}$, a waiting area of $50 \mathrm{~m}^{2}$, and 4-6 beds. II. Level Emergency Departments should have 400$800 \mathrm{~m}^{2}$ treatment area, 50-100 $\mathrm{m}^{2}$ waiting area, and 6-12 beds. III. Level Emergency Departments should have over $800 \mathrm{~m}^{2}$ treatment area, over $100 \mathrm{~m}^{2}$ waiting area, and 1220 beds.

An emergency service consists of the areas listed below:

- Entrance and triage area

- Information area

- Revitalization (resuscitation) area

- Acute care area

- Examination rooms

- Staff and their rest areas

- Management area

Emergency departments may include different special care areas outside the standard units. These areas are;

- Care section for pediatric patients,

- Heavy, traumatic patient care department that requires special care,

- Psychiatry department,

- Patient care department that tends to sexual exasperation and aggression,

- Long-term intensive monitoring section,

- Classrooms, halls that can be trained for medical students and inpatients,

- Transportation section that can provide the transportation of the patient and transfer it to another hospital when necessary,

- Communication section capable of providing emergency telephone service (C1plak, 2007).

Emergency Medicine Association of Turkey (EMAT, 2001) and the American College of Emergency Physicians (ACEP, 2007) introduced the following standards for emergency services;

- Emergency departments should be designed to provide the safe environment necessary for patient care. All applicants should be allowed to have an appropriate assessment and examination.

- Emergency departments should be designed to protect patients' visual and auditory privacy rights as much as possible.

- Radiological imaging, other diagnostic services, and laboratory services should have the characteristics to result in a suitable timeframe for each individual required.

- The shortest paths that can be reached to the Emergency Department from the main entrance of the hospital should be marked with illuminated signs. 
- The entrance of the emergency department should be at the same level as the floor, and the patients coming with the stretcher and wheelchair should be easy to enter. The emergency entrance should be covered, and patients should not be adversely affected by weather conditions when getting out of the vehicle or ambulance and entering the emergency department.

- Emergency departments should be designed in conditions that ensure the safety of employees, patients, and their relatives. There must be security personnel and fixed or hand-held metal detectors at the entrance.

Along with these general standards, the internal dynamics of the emergency departments must be compatible and working (Acem, 2014; Altındis and Unal, 2017).

\section{Space Requirements of Emergency Departments}

\subsection{Entrance and Triage Area}

The patient admission by ambulance should be separate from the patient admission to the outpatient. Separation of the patient admission with an ambulance will enable patients with high urgency to be separated from other patients and taken directly into the emergency area.

The first intervention to the patient is made in the triage area. Triage; is the system of determining the priorities of medical intervention in emergency departments based on the urgency of the patient's condition. As shown in Figure 2, it is facilitated for the patient to reach the relevant place with colored bands placed on the floor.

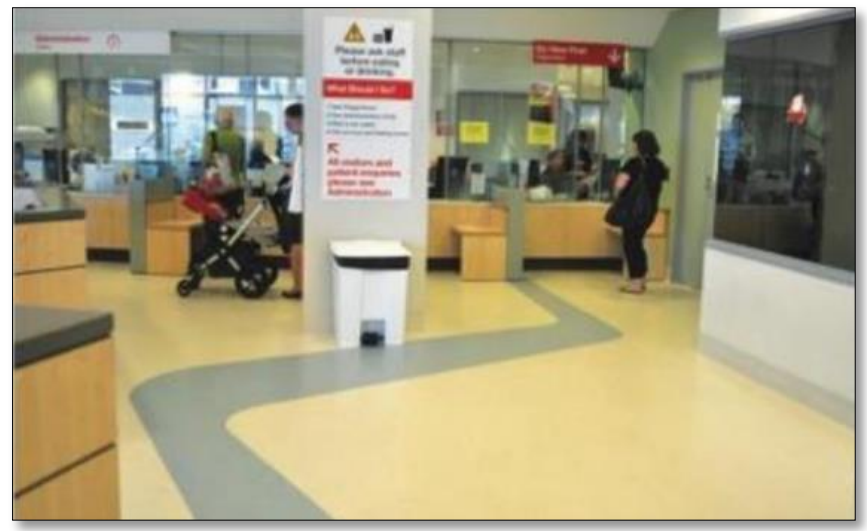

Figure 2: Triage Lines (Acem,2014).

- Black; means patient is dead.

- Red; means urgent intervention is required to save the patient's life.

- Yellow; means that the patient does not have the danger of life and does not need urgent care. Emergency care may be delayed.

- Green; means that no emergency intervention is required and the patient can wait.

Whether the emergency entrance is single or the outpatient entrance and the ambulance entrance are separate, the triage area should be in a place where all patients can see and 
reach all of them (Sen, 2009).

The equipment required to communicate with both the emergency room and the prehospital emergency system should be available in the triage area. For traumatized patients who can apply with enough stretchers, wheelchairs, and ambulances or out of the ambulance, the backboard and neck should be kept ready near the triage area.

\subsection{Information Area}

Information area; is the area where the patient is entered after the triage (separation) area. Patient information is recorded by the counselors by the patient or their relatives. The registration area should be close to the separation area and should be accessible from the treatment areas. In addition to its proximity to the entrance of the emergency room, a required space should be provided in the patient waiting area to prevent registration in the emergency room. Ensuring patient confidentiality should not be ignored during the registration process. In this area, there should be a sufficient number of personnel who can make patient entries, approve the examination requests, and do file archiving with the computerized system.

\subsection{Waiting Area and Toilets}

Sufficient waiting area should be created for patients and their relatives to wait in the emergency room. The area should be open and easily observed from the triage and information area. Seating seats should be comfortable, adequate wheelchairs and stretchers should be kept in this area. A comfortable environment should be created for long waits and the safety of waiting patients and their relatives should be ensured.

From the waiting room;

- Triage and counseling area,

- Toilets,

- Telephone and cash machines,

- Direct access to baby rooms should be provided.

The design of the emergency toilets requires special research like other public spaces. Toilets are one of the most important places in the health structure that requires the provision of personal needs. The toilets need to be designed in such a way that users can change their clothes and do their personal care. Toilets should have direct access to the waiting room. It should be able to respond to the care and needs of long-term patient relatives, as well as be used for disabled visitors and patients. For both sexes, areas for baby care should be reserved in toilets, and hooks for hanging clothes and bags should be available.

\subsection{Revitalization (Resuscitation) Area}

The revitalization room is used for the care of severely injured patients and critical patients. This area is the unit where the first evaluation and stabilization procedures of patients with severe trauma or patients with the poor general condition are performed. The revitalization room should be nearest to the emergency ambulance entrance. This area should be independent of other areas of the emergency room, but should also be placed nearby. All medicines and surgical materials required for life-saving and emergency intervention should be kept in the room. 
Revitalization room; a special resuscitation bed and the movement area that can be rotated 360 degrees around the bed should provide sufficient circulation space for staff and portable material, sufficient space for medical supplies, monitors, and storage.

In revitalization room, stretchers that can move in all directions, change the height, position and long life stretchers should be preferred. The area required for a single resuscitation bed is $35 \mathrm{~m}^{2}$. Portable additional light sources should be available in the room. The power supply of this room must be from the emergency current and provide an uninterrupted current (C1plak, 2007; Kurucelik, 2009; Sen, 2009).

\subsection{Acute Care Area}

The area of acute care is the area where patients who apply to the emergency department due to acute diseases are treated. In the acute care area, there should be a minimum bed area of $10 \mathrm{~m}^{2}$ per bed, a storage area for materials, areas where monitors will be placed, and the distance between the two beds should be a minimum of $2.4 \mathrm{~m}$.

\subsubsection{Emergency Patient Treatment Area}

The emergency patient treatment area should have $3 \times 4 \mathrm{~m}$ space for each stretcher. A comfortable transition to the main hospital connection should be ensured by considering possible hospitalizations and examination requests. Stretchers to be used in this area, should move in all directions, change the height, position, and have long-life stretchers. In the middle of this area, there should be a nurse observation station and a physician study area. Oxygen connected to the main system should be provided for each stretcher. In order to respond to possible emergencies, a sufficient number of airline materials and equipped emergency cars should be available, depending on the size of the area.

\subsubsection{Non-Emergency Patient Treatment Area}

They need less space than the emergency treatment area. It can be designed as closed spaces or open spaces. If the ambulance and outpatient entrance of the emergency department is separate, it should be close to the outpatient entrance and waiting area, but if there is only one common emergency department entrance, the revitalization area, and the emergency patient assessment area will be closer to the entrance, so the non-emergency patient assessment area may be further away from the main entrance (C1plak, 2007; Sen, 2009).

\subsection{Examination Rooms}

These areas include different assessment and treatment units, such as the intermediary room, isolation room, child patient assessment, and treatment room. The doctor, nurse room and rest areas, nurse observation station, registration area, storage, clean and dirty material room, and toilets also included in the main structure of the emergency room. While designing patient care areas and working areas of all staff;

- Proximity to the emergency entrance,

- Proximity to other services of the hospital,

- The relationship between patient care areas and each other, are the three main factors that need attention. 


\subsubsection{Plaster Room}

All materials required for plaster and splint interventions should be available in this area. It should also include a sink with a strong drainage system, considering that there may be clogging with plaster waste. It should be close to the radiology unit and there should be a film reading sign in the room. There should be service and control panels, plaster and bandage storage units, x-ray imaging panels, workbench, and sink in the room.

\subsubsection{Isolation Room}

The isolation room should be a closed area and should be designed as an area where individuals with highly infectious diseases, such as tuberculosis, measles, chickenpox, or those with open wounds are evaluated and treated. The ventilation system should be separate from the central system or air filters should be used. The room should have a sink, preferably a shower system. It should be placed in an area near the outpatient entrance.

\subsubsection{Decontamination Room}

Persons who are contaminated with radioactive material in factories in wars or industrial environments are taken directly to this room. In the decontamination room, which should be at the level to intervene more than one patient at the same time, resuscitation and treatment materials, and, most importantly, a shower should be available. After the brought persons are decontaminated, other treatment procedures are started. The decontamination area should contain more than one stretcher. The decontamination area is divided into two as hot and cold. The hot zone is the area where decontamination is performed, and the cold zone is the area where the patient passes after the decontamination process. An area for dressing should be done in a cold area.

The decontamination area should be close to the ambulance entrance. However, it should not see the waiting room and other incoming patients. The area should have a direct relationship with the external area, the drainage system should be separate from the hospital's installation. Storage should be created within the decontamination area and kept separate from hospital waste.

\subsubsection{Psychiatric Patient Care Room}

Psychiatric patient care should be positioned within easy reach of the security officer and the healthcare team. Patients who are prone to suicide and who may harm themselves and their surroundings generally care in this room. There is no medical equipment in the room for preventing harm from the patient. The patient in the room and inside should be monitored with special observation spaces or hidden cameras. The most important feature is that the rooms should only be locked from the outside, not from the inside. Acute mental care areas should be designed close to closed examination areas. In order to ensure confidentiality, patients who come to acute mental care areas should not be passed through the emergency care area, privacy should be ensured.

There should be an emergency and call system in psychiatric patient care areas. The psychiatric patient care area is ideally composed of two parts. These areas are explained as the interview room and examination room.

There should be two doors in the interview room. If necessary, only the door that the 
personnel can exit should be lockable from the outside, not from the inside. The interview room should be painted in soft colors, insulated from outside sounds and noise, furnished with soft materials, have a fire system, be suitable for the escape of personnel when necessary, and a warning system should be available at each exit. Patients should be prevented from reaching the ventilation system. Electricity and medical gases should be out of reach of patients. Patients should be directly observable. The interview room should be at least $16 \mathrm{~m}^{2}$.

The examination room should be next to the interview room. It should have all kinds of patient care materials and should be at least $12 \mathrm{~m}^{2}$ (C1plak, 2007; Sen, 2009).

\subsubsection{Pediatric Patient Care Room}

It will be appropriate to evaluate child emergencies in a separate area in order to prevent noise pollution in the emergency room and not to see severe traumatic resuscitation patients. If the annual number of pediatric patients is more than 15000, a child emergency area should be created in the emergency room or adjacent. A separate resuscitation and trauma patient care area may be needed in the pediatric emergency. If the resuscitation area is close to the pediatric emergency area, the pediatric patient can be admitted to the pediatric emergency department after treatment in the adult emergency resuscitation area. So it should be close to the resuscitation area.

Child emergency areas should be designed flexibly. The walls should be avoided in line with the possibilities. While a child emergency is designed in a separate children's emergency or a children's hospital outside the emergency room, general emergency design principles are used. Patient care areas and area sizes are the same. All rooms must be equipped and equipped for patient control. However, playgrounds should be created within the waiting room and patient care areas. There should be rooms to monitor pediatric patients near the game rooms. Things to consider in the child emergency area can be explained as follows;

- In order to make children psychologically comfortable in the emergency room, attention should be paid to the use of materials such as pictures and toys as seen in the Figure 3 example. Special game halls should be built under the supervision of the supervisor.

- Toilets, showers, patient baths and sinks should be made according to the size of the pediatric patients.

- Special stretchers should be used for pediatric patients (Acem, 2014).

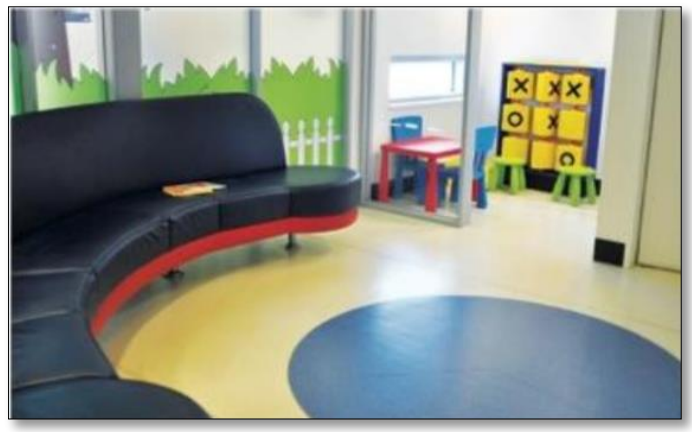

Figure 3: Pediatric Patient Care Waiting Room (Acem,2014). 


\subsubsection{Doctor and Nurse Room}

The doctor's room should be placed centrally. It should have $\mathrm{m}^{2}-1 \mathrm{~m}^{2}$ for each physician in the office. Area; It should also allow observation of patients other than filling files, meeting with relatives or physicians. Ease of communication should be provided with a sufficient number of telephones and other areas of the emergency room and hospital. Teaching materials, reference resources, and textbooks should be available in this area. The nurse should be considered as the center of the emergency room. All areas, especially the emergency patient assessment and treatment area, should be placed as " $U$ " around the nurse work area as much as possible. This centralization will enable the staff to follow all the patients. Necessary equipment should be provided in the nurse working area for communication with the separation area (triage), registration, pharmacy, and other areas and other services of the hospital. There should also be a central system for drug and material requests. It will be easy to keep the laboratory, $x$-ray requests, or other important papers ready in this area thanks to an open and double-shelf system.

\subsection{Diagnostic Areas}

\subsubsection{Radiology and X-Ray}

If the annual number of patients coming to the emergency department is between 20,000 and 25,000, radiology rooms should be considered in the emergency department. If the main medical imaging area of the hospital is close to the emergency room, it is not necessary, but considering the number of patients to increase, it will be useful to establish a medical imaging center in the emergency room so that the emergency room can be selfsufficient. The x-ray room should be close to the trauma patient care area (Acem, 2014; Sen, 2009).

Whether radiology and x-ray rooms will be established and resolved in the emergency room should be decided upon the evaluation of the number of patients in the past. The fact that these rooms have expensive systems is also effective in this decision. Today, in most emergency departments, there is no tomography device because it is expensive. The minimum dimensions that should be of the radiology room are shown in Figure 4.

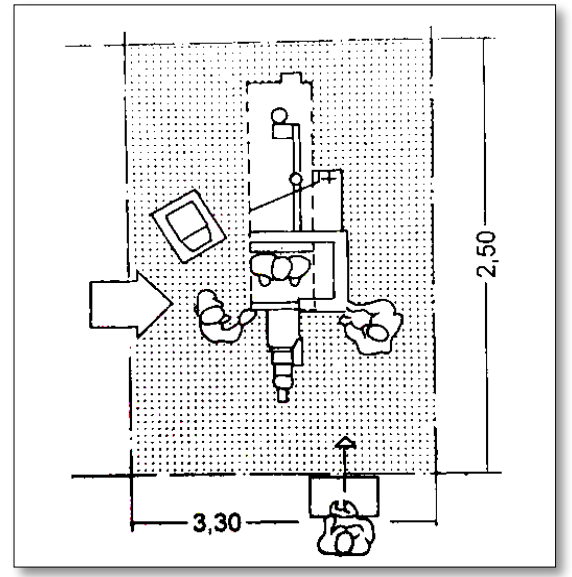

Figure 4: Required Area for X-Ray (Neufert, 2015). 


\subsubsection{Tomography}

Today, most of the newly designed emergency services are designed to be in computerized tomography (CT) device. Factors such as the number of patients, type, number of traumatized patients, intensive care hospitalization rate, and annual estimated CT requests should be taken into consideration before the establishment of tomography technology. The presence of CT in the emergency room in reference hospitals operating as a trauma center will increase the speed and level of patient care. Even if the CT device is not in the emergency room, it should be located right next to the emergency room and a direct connection to the emergency room should be provided (Acem, 2014; Sen, 2009).

\subsubsection{Ultrasonography}

In recent years, the use of ultrasonography has become increasingly common in emergency rooms due to the increased image quality and the production of smaller and per patient portable devices. The presence of an ultrasonography device in the emergency room will allow patients who are unstable to be evaluated by radiologists or other physicians without the need for transplantation. The minimum dimensions that should be of the ultrasongraphy room are shown in Figure 5. The possibility of recording and printing of the ultrasonography device to be used in the emergency room will provide additional benefits.

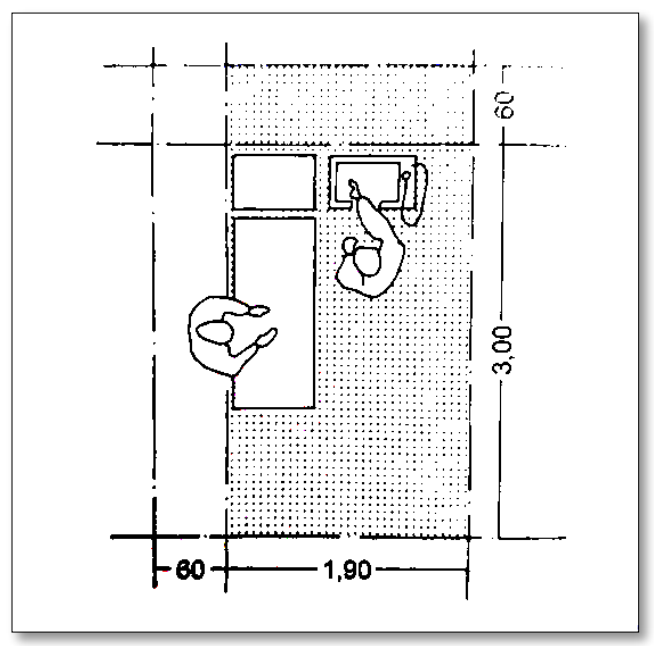

Figure 5: Required Area for Ultrasonography (Neufert, 2015).

\subsubsection{Other Imaging Methods}

The rapid response of other imaging methods to emergency requests is one of the factors affecting the emergency patient care rate. These examinations should be performed 24 hours a day, 7 days a week, especially in reference hospitals. Other imaging possibilities that can assist with the functioning of the emergency room are as follows;

- Magnetic resonance imaging

- Angiography 
- Nuclear medicine imaging (Ventilation-perfusion scintigraphy of the lung, scintigraphic studies for trauma patients)

- Cardiological imaging (Echocardiography, Doppler)

- Contrasty studies

\subsubsection{Laboratory}

Laboratory facilities and its proximity to architecture are the important factors affecting the quality and speed of patient care in the emergency room. Using computerized recording and tracking systems is just as useful as architectural proximity. Entering all laboratory requests via computer saves time and minimizes possible errors. The nurse takes the blood, puts it in the tubes and labels, the secretary in the recording area enters and approves the computer, the emergency staff leaves the blood to the lab, or the blood is transmitted to the lab via the scuba system, and the result is taken from the computer by the physician. In modern emergency departments, even if it is not as close as a laboratory, blood is transmitted to the laboratory without the need for additional staff thanks to the scuba systems operating with air pressure, and the results can be followed through the computers located in the doctor's or nurse's work area. If there is no such system, it is useful to have a mini-laboratory inside the emergency room and used only for emergency patients. If this opportunity cannot be provided, the emergency room and laboratory should be placed as close as possible. A microscope, a sufficient number of chemical analyzers, incubators, and centrifuges must be kept in the mini-laboratory that will be located in the emergency room. In the laboratory work area, hot and cold water source sinks, vacuum systems, air and gas outlets, and electrical connections connected to the emergency service should be provided. In order to store blood, it will be appropriate to have a refrigerator with a temperature indicator and an alarm (C1plak, 2007; Sen, 2009).

\subsection{Management Area}

The management area is the area where administrative and quality control services are provided, and the training and research role of emergency services is fulfilled. The office should be considered for each manager, assistant manager, nurse trainer, specialist staff, secretary, psychologists, social security officer, and administrative consultants.

In emergency departments with a large area, a multi-purpose meeting room should be considered within the management area. The total management area should be at least $4 \mathrm{~m}^{2}$ / 1000 total number of patients. Each office should have at least $9 \mathrm{~m} 2$ of space and consist of a desk, computer, telephone, and chair (Acem, 2014; C1plak, 2007).

\subsection{Storages and Archive}

Storages are; consist of a clean material room, dirty material room, discharge areas, and material storages. The clean material chamber should be large enough to store sterilized medical supplies. Dirty material rooms should be accessible from all clinical areas and should be designed to store medical and clinical materials that need to be cleaned. The storage room should be built in addition to the storage units in the clinical area and its total area should be 2,2 $\mathrm{m}^{2} / 1000$ yearly. The storage room should have a beverage compartment, emergency tool storage, cleaning room, patient bath, shower, toilet, and bath. 


\section{General Design Factors of Emergency Departments}

\subsection{Technical Needs}

\subsubsection{Transport and Parking}

Emergency care areas should be on the ground floor to facilitate transportation and increase the speed of transportation. The section of the patient that will be taken in from the ambulance should be covered so that the patients are not affected by the weather conditions. The covered parking area should be reserved for police vehicles and ambulances.

There should be signs indicating the emergency direction at the entrance of the hospital. Emergency entrances should be close to public transport. Suitable parking places should be available for vehicles other than ambulances, parking places should be close to the entrance and should be positioned so as not to block the entrance to the emergency service. Outpatient entrance and ambulance entrance should be kept separate from each other.

Emergency services must have a single entrance to protect patient privacy and security. Stretchers should be available at the entrance of the emergency department.

\subsubsection{Site/Location Selection}

Site selection is one of the most important factors affecting emergency care quality and emergency service. The emergency room should be flexible, developable, changeable according to the plan chart applied, and should be positioned in a way that does not obstruct the main transportation lines.

Although the emergency room gives an independent view with its location on the ground floor with a separate entrance, it is also in close contact with all the other units of the hospital, as well as the health, safety, and social services in the region.

In the emergency department, patients are admitted without discrimination and are then directed to the relevant department. Therefore, the location of the emergency room within the hospital should ensure that it is linked to all other departments.

\subsubsection{Lighting}

Each clinical area should be equipped with task lighting which can be directed to areas in which it is required. High-quality light is required in all urgent areas and rooms. Soft colors that are not reflected directly in all emergency areas should be preferred.

Ambient lighting in an emergency department should provide a calm atmosphere and, as much as possible, make an attempt to mimic the diurnal rhythm, through the dimming of lights at night-time. Not using more light than necessary is important for both patient comfort and employee satisfaction. In patient examination rooms, instead of ceiling lighting, wall-mounted and adjustable light sources should be preferred to prevent patient's eye disturbance. In the patient examination rooms, both sunlight can be used and the privacy of the patient is protected by using high-settled windows.

Daylight ingress should be considered in the emergency department design however, glare should be eliminated and electric lighting should be designed to supplement and balance incoming daylight (Acem, 2014; Ciplak, 2007). 


\subsubsection{Sound Attenuation}

In the emergency departments where hundreds of people enter and leave every day, there is a high rate of noise. Apart from this, the voices that provide the transition from outside to the hospital also contribute to the increase of this noise turmoil. Hospitals are places where they should have a quiet and calm environment in terms of their service, therefore, hospitals should be soundproofed.

As the materials to be used in sound insulation, antibacterial melamine foams, which are the most ideal product for a hygienic environment, are used. These foams provide hygiene and are not dangerous because they do not melt in case of fire or high-temperature exposure due to their fireproof properties.

Healthcare users are positively or negatively affected by their environment. Noise in space is one of the problems that affect people negatively. The noise, which changes the quality of the rooms by deteriorating the calmness of the spaces, is even more important in the hospital environment.

According to WHO (World Health Organization), in health structures;

- Creation of areas where diffused noise cannot enter,

- Reduce noise, eliminate unnecessary noise sources,

- To reduce the noise with the measures to be taken from the source,

- To prevent the noise from going out of the source,

- Noise emitted outside the source should be kept within the narrowest limits.

Insulation is a mandatory need in hospitals, and in the hospitals where insulation is made, the work efficiency of the employees will be high, and the patients will get their health in a calmer environment.

Emergency departments should be designed so as to minimize the transmission of sound between adjacent treatment areas. To reduce the noise level, single rooms, soundabsorbing plates, soft floor coverings, and solid glass, doors, and walls should be used (Acem, 2014).

\subsubsection{Door and Corridor Features}

In the emergency room, more precisely, the doors in the entire hospital should be able to pass a special patient stretcher or bed together with the staff. Doors should be open in both directions, if space is possible, two-winged doors should be preferred. Doors with this feature will provide two-way ease of use.

Generally, corridors should be avoided unless needed in an emergency room, and if necessary, they should not prevent the passage of two patient beds or a patient bed and a stretcher. In addition, a corridor should be designed considering the stretcher exit and return from the rooms. While designing, the number of doors to be opened to the corridor is also effective in the width of the corridor (Acem, 2014; Ciplak, 2007; Sen, 2009).

\subsubsection{Wall, Floor and Ceiling Materials}

Since patients and other people coming to healthcare structures are affected by the infection, the internal materials used in the healing of health centers, hospitals, and other health services must be special. In emergency services, the materials should be durable, easy to maintain and clean, stain, wear, fire-resistant.

Attention should be paid to wall design in hospitals. In addition to the divider and carrier 
feature, the walls also have an insulation feature. Wall materials should be easy to clean and resistant to water and impacts. Vinyl, which is resistant to abrasion, tearing, and impacts and has a life span of 6 to 10 years, is among the materials preferred in healthcare structures.

To provide sufficient wall protection due to stretcher movements, wall protection tape should be used in patient treatment rooms and wall protection tape (see figure 6) with handles in the corridors where the patient passes as. Such applications will both prevent the walls from wearing out and help patients to hold on to the necessary conditions (Ozgen, 2014).

Flooring and ceiling materials in hospital buildings should be easy to repair and economical. The flooring should be made of non-slip material, easy to clean, waterresistant, resistant to abrasion, and impacts and should have acoustic properties that reduce sound permeability. The flooring material should be capable of supporting stretcher and bed movements on its upper surface.

When the studies are examined, the features expected from the flooring surfaces in hospitals are determined as hygienic, anti-bacterial, anti-static, non-flammability, and nonslip. The materials used in hospitals were determined to be marble, ceramic, mosaic, granite, PVC (shown in Figure 6), linoleum, epoxy, and marley (Kurucelik, 2009; Ozgen, 2014).

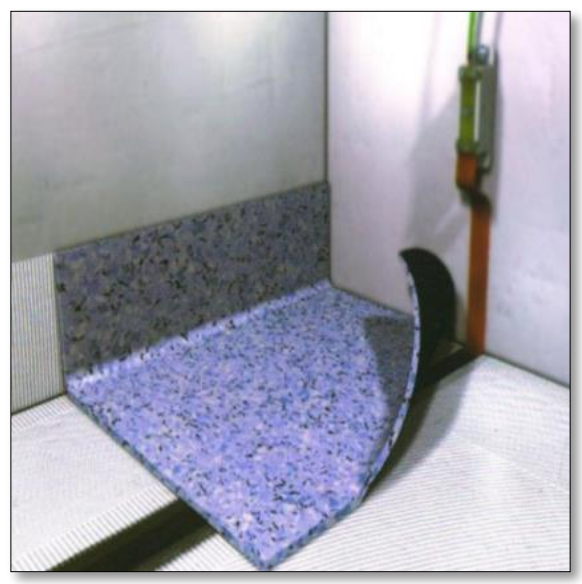

Figure 6: PVC Flooring (Sabin,2016).

Ceiling materials are important, like flooring materials, are water-resistant and easy to clean. When the ceiling covering is required, it should be selected from the material that allows easy and economical intervention to the installation.

Lighting and ventilation installations should be hidden by applying suspended ceilings on the ceilings. Thus, a more hygienic and aesthetic appearance can be obtained (Kurucelik, 2009; Ozgen, 2014).

\subsubsection{Ventilation}

Emergency departments are units that work 24 hours a day and are dense in terms of human circulation. Cleaning, heating, and cooling of the air in the emergency room is 
an important design factor. The purpose of providing air movements within the hospital is to prevent the spread of microorganism infections and dust.

In hospitals, air-conditioning systems should provide an airflow capable of maintaining average air temperature and humidity. Ventilation systems must have filtration and some of the air must be replaced with fresh air.

\subsection{Physicological Needs}

\subsubsection{Emergency Bed Placement}

The hospital bed is a bed specially designed for long term care patients with severe and life-threatening illnesses and injuries. These beds have the adjustable height, adjustable side rails, and electronic buttons to operate both the bed and other electronic devices which are near to the bed. It helps care workers treat patient complications during recovery.

In the acute care area, there should be at least $2.40 \mathrm{~m}$ clean gap between the emergency beds (stretcher). The minimum length for a bed should be $3.00 \mathrm{~m}$ (Acem, 2014). Medical equipment should be available in plastic or metal cabinets in close proximity to each bed in the emergency room, as shown in Figure 7 which is a photo of emergency cubicle.

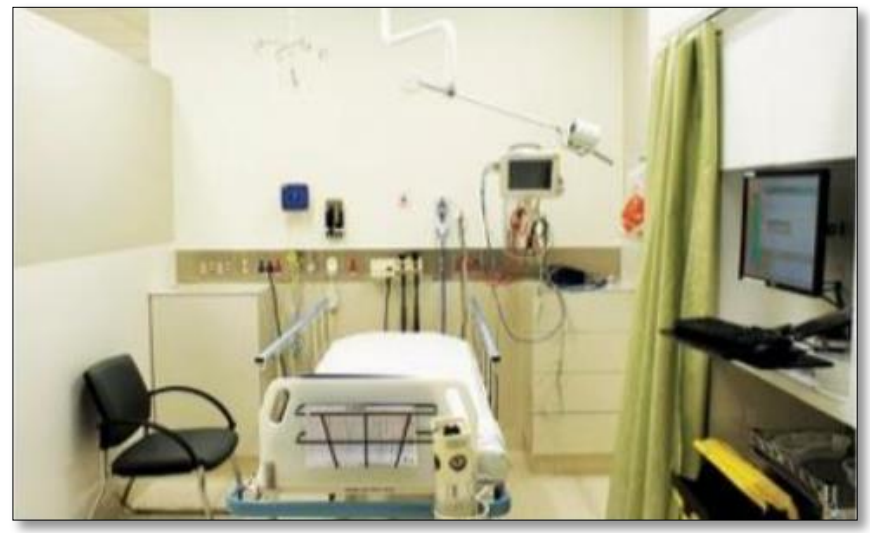

Figure 7: Emergency Cubicles (Acem,2014).

\subsubsection{Privacy}

In hospitals; it is important that both visual and acoustic privacy is provided. Users in the hospital space should be able to control social interaction. A regional sense of privacy should be provided that increases from the public to private.

All employees must respect patients' privacy and prevent confidentiality breaches. In addition, staff should ensure that one patient does not bother another patient. Here; the architectural structure of the emergency department plays an important role. While designing the emergency department, patient privacy should be considered.

Patient privacy and confidentiality are important issues. According to Architect Karakurt, this issue can be provided in the following ways:

- Ensuring the confidentiality of patient interviews and records.

- Placing windows and doors appropriately to ensure the patient's privacy. 
- The patient entrance to the hospital by ambulance should be visually separated from the patient entrance to the outpatient and the patient at the patient entrance to the outpatient should not see the patient coming by ambulance.

- Planning should be made by separating quiet areas from the noisy areas within the health structure (Karakurt, 2003).

For patient privacy, generally, emergency department cubicles should be available for one patient as shown in the Figure 8. Certain types of cubicles should include walls/robust partitions and a door for privacy and noise attenuation; especially those for pediatric patients, migraine patients.

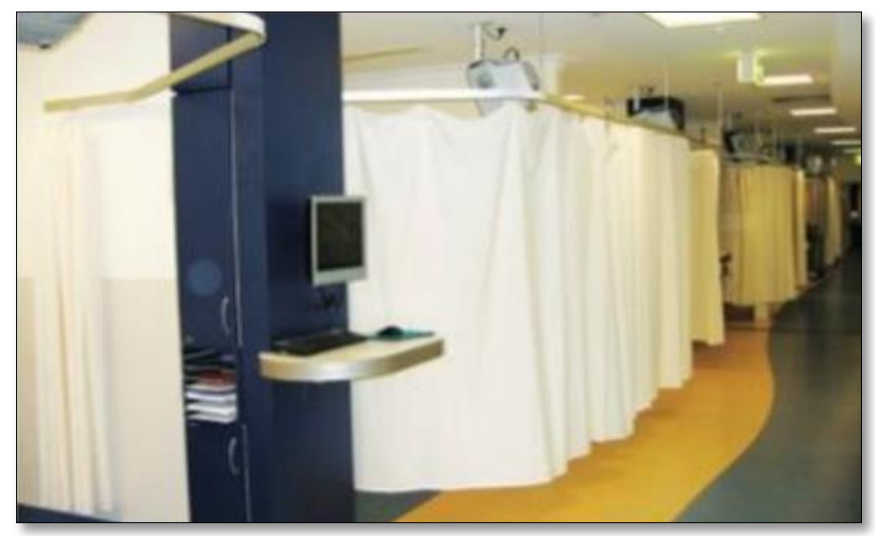

Figure 8: Hospital Cubicle Curtains (Acem,2014).

\subsection{Aesthetical Needs}

\subsubsection{Colour and Texture}

In architecture, color is a design element; together with form, space, and light, they form the components of the architecture. Beyond being a quality within the entire effect that color is perceived, it has many abilities such as affecting proportions, expressing scale, revealing unity and diversity, breaking the whole, hiding the part in the whole, distorting or establishing balance and symmetry, increasing or decreasing the effect of similarity or contrast. Color can also be used to read the order, to preserve the delicate border between chaos and chaos, and to capture the human scale.

Color choices in hospitals consist of soft colors. It is predominantly green, orange, blue, gray, and white colors are chosen (Ozgen, 2014).

\section{Findings of the Study, Conclusion and Recommendations}

\subsection{Findings of the Study}

There have been changes in the health structures from past to present and will continue after today. These changes and developments create new user needs. In this study, emergency departments were searched in line with user needs by searching related literature. Emergency departments are the most in contact with the patient. Considering the crucial role of the emergency department in providing urgent care, the design of physical 
environments to facilitate immediate, efficient, and effective patient care are of significant importance. In design, the priority should be to determine needs. The annual number of patients, number of personnel, integrity with the hospital are among these criteria. At the same time; a healthy, safe and comfortable environment should be created for patients, relatives, and employees. For this, emergency departments should be simple, flexible, open to development, safe, and well organized. In addition, technical, psychological, and aesthetic needs such as transportation, site selection, lighting, sound attenuation, door and corridor features, privacy, color, and texture should be considered. During the design; the need for innovation that may occur in the future should be considered, the use of technology, the creation of a suitable environment for patients and employees, the spaces should be planned with the patient's confidentiality in mind and integrity of the hospital.

\section{Conclusion and Recommendations}

Access to the emergency department should be easy and understandable, ambulance and outpatient entrance should be separated. Entrance and waiting areas should be designed to prevent human density and should be suitable for long waiting times. Toilets should be considered separately for patients, patient relatives, and staff. Emergency treatment areas should be located closest to the ambulance entrance and ensure that the patient is treated as early as possible. All necessary medical equipment must always be available in the emergency room. The required number of patient beds, stretchers, doctors, and healthcare professionals should be available. The emergency room should be close to the main imaging units of the hospital if there is no imaging area inside. The doctor and nurse rooms should be located in the center of the emergency room and should be in a position to observe the patients comfortably.

In addition, doors and corridors should be to the extent that stretchers and employees can pass together. Lighting should be done according to the needs of each area, so as not to disturb patients and employees. Necessary sound insulation and ventilation should be provided and a suitable wall, ceiling, and floor materials should be used.

Within this framework, the requirements of the user in the emergency areas have been examined in this study. The most important factor is the fact that users are composed of patients in the design of the emergency department. When it comes to saving lives with emergency response, user needs should be considered in detail and design should be made in line with these needs.

While designing health structures; problems and solutions should be determined, technological possibilities should be examined, and designs should be realized in the light of this information.

Hospital users should not only be considered as patients, the needs of staff and visitors should also be considered.

A sufficient number and quality of routers must be available for them to perform their transactions. At this point, triage directions should be applied. The emergency entrance should be easy to detect. Emergency patient entrance and outpatient entrance should be separated from each other, ambulance entrance should be located closest to the intervention area. Emergency departments are areas that are more crowded and have a higher flow of people than the general hospital. Treatment areas and waiting areas should 
be created with this intensity in mind.

The time spent in the waiting areas of the visitor group in the emergency departments is more than the other areas. For this reason, the areas where visitors can spend a long time, are comfortable and that will affect the users psychologically positively should be designed. There should be a space reserved for children in the waiting areas and should be positioned in a way that the parents can observe in the waiting area.

Corridor and door dimensions in the emergency room should be designed with sufficient width considering the stretcher movements.

Public toilets should be designed with users with disabilities in mind. At least one unit in the toilets should be reserved for disabled users.

Treatment and observation areas should be separated from each other in emergency departments and patient privacy should be ensured.

Materials used in emergency departments should be selected that are resistant to fire and intensive use, easy to clean, and antibacterial.

As a result; emergency departments should be designed to be able to respond to the patient who needs urgent help as soon as possible, to meet future needs, and to be flexible and adaptable.

\section{References}

ACEM, (2014) ,Australasian College for Emergency Medicine, Emergency Department Design Guidelines, Vol.3: 14-27.

Arsalan Gharaveis, D. Kirk Hamilton, Mardelle Shepley, Debajyoti Pati, Susan Rodiek, (2019), Design Suggestions for Greater Teamwork, Communication and Security in Hospital Emergency Departments, 28(8):1126-1139. https://doi.org/10.1177/1420326X19836209

Asena Kumsal Sen, (2009 Analyse And Reinterpretation Of Emergency Departments Over Users, Master thesis, Graduate School of Applied Sciences of Istanbul Technical University.

See also URL https://polen.itu.edu.tr/handle/11527/3327

Aysin Sevgi Karakurt, (2003), Critical Analysis and Evaluation of Hospital Main Entrances According to Design and Performance Criteria in Case of Turkey, Master thesis, Graduate School of Natural and Applied Sciences of Middle East Tecnical University. See also URL http://etd.lib.metu.edu.tr/upload/1078435/index.pdf

Debajyoti Pati, Thomas E. Jr. Harvey, Sipra Pati, (2014), Physiical Design Corraltes of Efficiency and Safety in Emergency Departments: A Qualitive Examination, 37(3): 299-316. doi: 10.1097/CNQ.0000000000000032

Dicle Aydin, Mehmet Uysal, (2010), Systematic Designing in Architectural Education: an Experience of Hospital Design, Archnet- International Journal of Architectural Research, 34(4): 458-466. See also URL https://archnet.org/publications/5354

Elif Özgen, (2014), Sağlık Yapılarının Genel Mekan Tasarımlarının Kullanıcılar Üzerindeki Etkisi ile Hacettepe Tip Fakültesi Hastanesi 7 No.'lu Kapı Girişinin Düzenlenmesine Bir Öneri, Master Thesis, Department of Interior Architecture and Environmental Design of Hacettepe University. See also URL http://www.openaccess.hacettepe.edu.tr:8080/xmlui/handle/11655/2319

Fatmanur Baran Atalay, Elif Bülüç, Dicle Aydın, (2017), Change of Hospital Designs Based on Architectural Program, Livenarch V-2017: Rejecting/Reversing Architecture, Trabzon, Turkey. See also URL https://www.researchgate.net/publication/320584185 Change Of Hospital Designs Based On Architectural Program

Gülcan Kurucelik, (2009), A Quality Assessment Model in Emergency Service Design of Hospitals, Master Thesis, Graduate School of Applied Science of Karadeniz Technical University. 
İlknur Sahin, (2016), Evaluation of Special Finishing Materials Used in Hospital Buildings Particularly Operating Rooms in the Context of Constructional Design Criteria, Master Thesis, Graduate School of Applied Science of Dokuz Eylül University.

NEUFERT Architect's Data, (2015), 39th Edition, Hospitals, pp. 302-329.

Nigel Bevan, (1999), Quality in Use; Meeting User Needs for Quality, The Journal of Systems and Software, 49: 89-96. https://doi.org/10.1016/S0164-1212(99)00070-9

Patricia A. Lenaghan, Nicole M. Cirrincione, Steven Henrich, (2014), Preventing Emergency Department Violence Through Design. https://doi.org/10.1016/j.jen.2017.06.12

Pinchas Halpern, Scott A. Goldberg, Jimmy G. Keng, Kristi L. Koenig, (2012), Principles of Emergency Department Facility Design for Optimal Management of Mass-Casualty Incidents, Prehospital and Disaster Medicine, 27; 204-212. https://doi:10.1017/S1049023X12000623

Selma Altındiş, Özgün Ünal,(2017), Situation of Turkey About Emergency Service Quality Standards, Journal of Biotechnol and Strategic Health Research, 2: 51-59.

See also URL https://dergipark.org.tr/tr/pub/bshr/issue/31524/345368

Serpil Karatas Ciplak, (2007), Emergency Department Design, Master Thesis, Graduate School of Applied Science of Dokuz Eylül University. See also URL http://acikerisim.deu.edu.tr:8080/xmlui /bitstream/handle/20.500.12397/8490/213084.pdf?sequence $=1$ \&isAllowed $=\mathrm{y}$

Zahra Zamani, (2018), Effects of Emergency Department Physical Design Elements on Security, Wayfinding, Visibility, Privacy, and Efficiency and Its Implications on Staff Satisfaction and Performance,12(3): 72-88. https://doi.org/10.1177/1937586718800482 